\title{
Metaheuristics for Optimization Analysis on Urban Public Transport
}

\author{
Mariana Brito Batista \\ Computer Science Department \\ University Federal of Tocantins \\ Palmas/Tocantins - Brazil
}

\author{
Warley Gramacho da Silva \\ Computer Science Department \\ University Federal of Tocantins \\ Palmas/Tocantins - Brazil
}

\begin{abstract}
Palmas in the state of Tocantins is the youngest capital of Brazil and the one with the highest growth rate between 2013 and 2014 according to the Brazilian Institute of Geography and Statistics (IBGE). Presently, more than $85 \%$ of individuals live in urban centers and often need to use services related to public policies, including urban public transport. To meet this demand, the city has a company that manages and provides this service. That, however, has regularly been increasing the usage fee. These essential expenditures for the performance of services if optimized could be lower without affecting the availability and effectiveness of urban public transport. Therefore we propose the use of optimization through metaheuristics, which are algorithms that work with a certain level of randomness that throughout the process seek to find a better possible solution. Thus, this work will analyze how this problem behaves in metaheuristics applying in the scenario of Palmas, Tocantins - Brazil and discuss the optimal results expected by the algorithm, as well as identify the optimization ranges in which the metaheuristic will fit at the end of its processing.
\end{abstract}

\section{General Terms}

Optimization, Vehicle Scheduling Problem

\section{Keywords}

Metaheuristic, Optimization, Vehicle Scheduling Problem, bus, Iterated Local Search

\section{INTRODUCTION}

Palmas is located in the center of Tocantins, which is a state of Brazil located in the north of the country. It has the highest population growth in the region according to IBGE [16] that classified the city as a medium-sized, because it contains more than 100, 000 inhabitants and less than 500,000 with an estimated population in 2019 of 299,127 , more than 70,000 inhabitants that in the last census. In a city of this size, locomobility is extremely important for individual maintenance and survival.

Considering the context of constant population growth and development of Palmas, the data collected by IBGE [17] are consistent to the survey on the vehicle fleet census found in the capital, in which more than 187,000 vehicles were deployed generally present in the city, being more than $41 \%$ automobiles $(77,036), 26 \%$ motorcycles $(49,353)$ and $33 \%$ referring to other types of vehicles, in which we can highlight in this portion one of the main means of transport present in a city, the bus and minibus, used mainly in public transport with about 2,222 vehicles like these circulating in the city of Palmas. The capital has the largest fleet of buses in the state, followed by the city of Araguana and Tocantinpolis, and it is in 35th place at the national level, beating cities with a larger population, such as Porto Velho - Rondnia with 369,259 inhabitants and So Jos dos Campos - So Paulo, with 533,501 inhabitants.

According to a report developed by the Agency for Regulation, Control and Supervision of Public Services of Palmas (ARP) published in this area by a news portal [7], around of 190 vehicles are made available by Seturb (the company responsible for public transport administration), which carry more than 1.7 million passengers per month.

\section{Public transport individual usage fares of the last six years in Palmas - TO}

\section{5}

2016

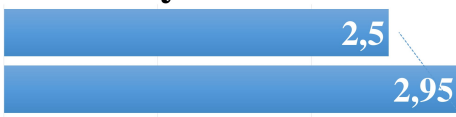

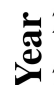

ङ 2017

2019

2020

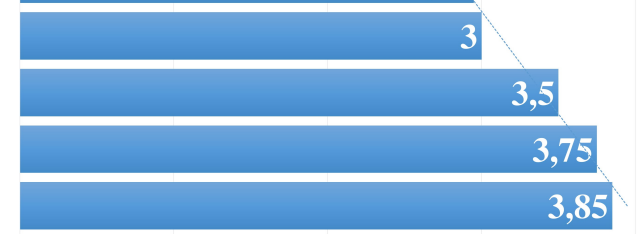

0
4
2

Usage fare $(\mathbf{R} \$)$

Fig. 1. Representation of the increase in the fare of use of public transport in Palmas - Tocantins of the last six years. According to the trend line, it can be observed a characteristic of predisposition to the annual increase in the price of the ticket charged by the public transport company of the city and regulated by the city hall.

Over the years, an increasing transfer of costs can be observed by increasing the usage fee for users (observed in detail in the image 11, then, aiming at minimizing the maintenance costs of the city's 
public transport service without altering or compromising the quality, in this work, it is proposed the use of iterated Local Search (ILS), which is a computational method for finding optimized solutions to complex problems by applying local search repeatedly in initial solutions obtained by disturbances of a locally optimal solution that was previously visited, and that in this situation will optimize the amount of vehicles used addressing the vehicle scheduling problem (VSP) in this real context.

The organization of this paper is as follows. In the next section, an overview of VSP applications is given and their relevance on the mobility aspects. Then, the solution approach show us the computational and the mathematical procedure for the verdict of the problem and a analysis of the expected result, which are presented in Section 3. This paper shows some possible future applications and concludes in Section 4.

\section{VEHICLE SCHEDULING PROBLEM (VSP)}

\subsection{Urban Mobility : Relevance of the problem}

There are several adversities related to urban mobility, it is assumed that traffic congestion costs around of $\mathrm{R} \$ 98$ billions per year in the largest metropolises of the country, this estimate being, considering the damage related to the time of production not made, and the extra expenses with the fuel [4].

According to a report released by the federal council of medicine in 2019 , every hour, 5 deaths are associated with traffic accidents with more than 380,000 fatalities in the last 10 years and 1.6 million injuries that cost more than 3 billion to the Unified Health System (SUS) [13], which is the public health system of Brazil, and 40 billion annually, whether recklessly, roads and/or precarious vehicles [4]. Palmas contained only in a period of 9 months about 30 deaths associated with speeding found only in the Master Plan of the capital, and about 121,000 electronic fines detected by sparrows being $87 \%$ for speeding and $11 \%$ for advancing the traffic light [31].

Since the space on the streets is being competed by the growing number of automobiles, consequently practices for optimizing the use of urban mobility should be adopted. For this to happen, more efficient public transport for its users is a great option, as in general they are constantly slower and uncomfortable than private vehicles.

\subsection{VSP on Literature}

The VSP has as central definition the search for a script that contains a scheduling of a fleet of vehicles optimized to meet a certain objective.

In this work, it can be observed the evolution of the description and the parameters related to the problem. Some studies in the 1950s began to emerge on problems related to the application of schedules in manufacturing, with the use of mathematical models to indicate the relevance of new production models in industrial activities, such as Melvin et al. work [25] that brings the programming of an operation as a problem to be solved in order to optimize a process. Another important work for the proposal was Johnson's rule [18] that describes the method of scheduling tasks in two work centers in which it aims to find an optimal sequence of activities to reduce production.

In the article of Clarke et al. [5] is highlighted for the first time a problem of vehicle programming in which it is known to this day for these name, the work develops an iterative procedure that allows the rapid selection of an optimal or almost optimal route for a fleet of vehicles. And despite being known to be one of the pioneers for describing a vehicle scheduling problem, the article points to the work of Dantzig [8] as the first that formulated mathematically. The problem related to vehicle dispatch, in which added in the formulation the demand and multiple capacity of vehicles, features these very important to the current problem of vehicle programming. The work of Muller [22] defines the VSP as being the combination of two types of problems, the assignment, in which elements of a given set are assigned to another different set, and the service problem, where several elements (or only a subset of them) need to be placed in a viable or optimal (sequence) order. The article of Biondi [2] aims to deal with heuristics for combinatorial optimization and raises several assumptions so that the solution is optimized in a short period of time relative to complex operations. Such as, using iterative algorithms that change the values of the parameters at each iteration and point to its conjuncture of solutions at the lowest cost.

In Foster's work [12] the author proposes the use of the entire programming method in order to synthesize the mathematical formulation for the VSP solution and insert new restrictions that accompany it in real-world situations, such as distribution by routes and schedules during weekly activity. In Bodin's work [3], a vehicle schedule is a sequence of pickup and/or drop-off points along with an associated set of $\mathrm{N}$ arrivals and departures. The vehicle must cross the points in the designated order at the specified point $\mathrm{N}$ times. When arrival times at nodes and/or arcs are set in advance, the problem can be called as a scheduling or scheduling problem. In the work of Filipic [11], the authors apply the use of genetic algorithm to solve the programming problem, although not specifically dealing with vehicles, the author mentions that it is a type of approach that relates any type of scheduling of the real world. Optimization is performed in two phases. First, a greedy heuristic procedure is activated to generate an initial schedule, that is, a solution. Programming is further improved using the evolutionary algorithm. He assumes the schedule obtained by the heuristic procedure as the father of the initial population. It then generates descendants from the parent by introducing minor changes to start times. The changes are implemented in such a way that the constraints remain satisfied. Of the descendants generated, the one that represents the schedule that most reduces the target overload becomes the parent for the next generation. The improvement algorithm proceeds until the given number of generations is reached.

In Steiner's paper [29] the author developed the problem as one of the sub-solutions using operational research techniques for the school transport optimization scheme in the city of Curitiba - Paran, Brazil, that achieved significant improvements that impact costs of the service when using Whole Linear Programming Problem to get the capacity and optimal amount of buses and apply the cheapest insertion heuristic.

In the article of Deniz et al. [10] the authors developed a mixed whole model to find the ideal number of vehicles with a minimum cost. Because of the complexity of the problem, they proposed some heuristics. Computational results reveal that heuristics return exceptionally good solutions at a very small processing time and probably perform well for larger instances.

In Situ's work [27] the authors analyze the optimization models for the problem of programming vehicles in the public transport network. The departure time model and departure interval model are formulated and heuristic algorithms have been developed to solve the models, which in turn optimize the start time and interval and have been applied in the city of Guangzhou in China. In the work of Gleidson et al. [28], the authors used the metaheuristic Iterated Local Search (ILS) for the resolution of the VSP with real scenarios for optimizing the service of several public transport companies in Belo Horizonte - Minas Gerais. 


\section{SOLUTION APPROACH}

\subsection{Metaheuristic}

Optimization is the process of finding the extremes of a given function, whether it is minimal or maximum, within a defined space. Usually are processes accompanied by complex problems that require techniques for resolution, among one of the most used currently, the metaheuristic [15].

In its explicit definition, according to Laporte [23], metaheuristics is an optimization technique that uses exploration characteristics and intensification iteratively through a heuristic. Being the first property related to the solution search space, and the second to the expertise acquired during the process of searching for the solution's "optimizeability". It intends to escape from great locations through the often process of randomness imposed along with the determined heuristic.

According to Melo [21], heuristic techniques use shortcuts to find a viable solution to a complex and impractical problem in executable processing time, by using some knowledge about the set of solutions. The greater the algorithm's understanding of the problem, the smaller the space to be explored by heuristics. In order to meet the need to find satisfactory solutions to problems that even for heuristics are complex and large, metaheuristic techniques are used that generally use initial solutions that are improved with the passing of the processing until it reaches a stop criterion.

\subsection{Iterated Local Search (ILS)}

The work of Thomas [30] was the first that named the algorithm Iterated Local Search. According to the author, the algorithm applies local search repeatedly in initial solutions obtained by disturbances of a locally optimal solution that was previously visited. Besides having a high efficiency when applied in combinatorial optimization problems, it has a very simple conceptualization, as well as its implementation and has high adaptability characteristic that covers the application in several combinatorial problems. In local search algorithms, we can observe easy situations of solutions stuck in local minimums. This requires some kind of attitude on the part of the algorithm to escape and continue to seek possible better solutions. One of these actions taken is the disturbance, in which such movement has to be greater than that provoked by the current local solution.

In Loureno's paper [19] we have a more specific approach to the algorithm. According to the authors, there are four important characteristics of ILS for its implementation, the initial solution, the disturbance, the acceptance criterion, and the local search. The initial solution defines where the starting point of the algorithm will be, that is, ILS will start from $s_{0}$ to $s^{\prime}$ in a solution space S. The sooner it is interesting to achieve new results, the greater the importance of a great initial solution. With the disturbance, ILS has the possibility to escape from great locations. The big question about is, how strong this movement should be, because if the disturbance is weak, the solution can regress, do not take effect, or even ensure a small exploration of the search space $\mathrm{S}$, and if it is very strong, the search will be little directed, thus doing a random search, which makes chance perhaps offer an optimal solution. Ideally, the level of disturbance of the algorithm varies according to the problem that will be solved, for example, for the problem of the traveling salesman, small disturbances are considered good for an optimal solution, while for the problem of quadratic assignment for which experimentally a relatively large perturbation size seems to be necessary.
The characteristic on the acceptance criterion, means the definition of what is accepted or not as the current solution. Together with the disruption, the acceptance criterion can be used to intensify and/or diversify the search. For the local search feature we have the practice of the research used to find the optimal solution. ILS behavior depends heavily on the built-in heuristics, which can turn out to be very different. We can say that the better the local search, the better the corresponding ILS. Any local search based on metaheuristic approaches, such as taboo search or simulated annealling, can be used and can generally result in good performance. According to the authors, the use of taboo search as embedded heuristics generates a very effective iterated local search for programming problems. In algorithms that use ILS for optimization processes, there are major concerns related to optimal global solutions, for this to occur, the combination of the disturbance-acceptance criterion determines the relative balance of intensification and diversification and should receive particularly strong attention. Major disturbances are useful only if they can be accepted, and this occurs only if the acceptance criterion is not too biased toward better solutions. ILS algorithms have been successfully applied to various combinatorial optimization problems. An example of success is the application of the algorithm to scheduling problems like this to be implemented in this present work, which are the Congram's algorithm [6], store flow scheduling problem [32], and workshop scheduling issues [20] or the same application, but just in a different scenario, like in Gleidson et al. [28].

\subsection{Proposed Solution}

Then, looking at this, the mathematical formulation of the Circulation Problem for the vehicle scheduling problem according to Cassio [1], with the minimization proposal given by Steiner [29] and constraint variables described in Gleidson et al. [28] is given by:

$$
\min z=\sum_{i=1}^{K} X_{i}
$$

s.a.

$$
X_{i}=\sum_{j=1}^{v k_{i}} x_{j}
$$

$$
X_{i} Q
$$

$$
\begin{gathered}
x_{j}=\left\{1, i f\left(O_{v_{i, j}}=\emptyset, v_{i, j}=1\right)\right. \\
0, \text { otherwise }
\end{gathered}
$$

$$
\begin{gathered}
d_{j} \geq a_{i}+t_{i, j} \\
v=\left\{1, \text { if } A_{d_{i}}, A_{a_{i}}=1\right. \\
0, \text { otherwise }
\end{gathered}
$$

$$
\sum_{i=1}^{K}\left(\sum_{j=1}^{v k_{i}} v_{i, j}\right)=V
$$


Where:

$-X_{i}$ : The amount of buses per public transport station $i$ to be minimized.

$-Q$ : Maximum bus quantity.

$-x_{j}$ : New bus available for travel $\mathrm{j}$.

$-K$ : Total number of stations.

$-v k$ : Total amount of trips per season.

$-d_{i, j}:$ Current departure time, next in station $\mathrm{i}$.

$-a_{i, j}$ : Current arrival time, next in station i.

$-v$ : Unit travel that corresponds to a $d_{i}$ and $a_{i}$.

$-O_{v i, j}$ : Bus that is connected to the trip $v_{i, j}$.

$-t_{i, j}$ : Time between trips.

$-V:$ Total amount of trips.

$-A_{d i}$ : Effective action of the departure trip i.

$-A_{a i}:$ Effective action of the arrival trip i.

In which the objective function (1) minimizes the amount of buses used in the solution. Equation (2) defines the set of buses in the solution by station. The restriction (3) concerns the upper limit of the solution. The condition (4) defines the equity by which it defines the presence of a bus in the solution, so a new bus will only be added, if for some reason of searching a bus is not available and a trip needs to be made. The restriction (5) indicates the lower limit of each journey, so a new journey can only be made if the current journey has ended and has respected a time for boarding and disembarking. The equation (6) indicates the validity of a trip, thus being a true trip only the one that has already gone through a departure and an arrival. And the last equality ensures the final amount of trips to be equivalent to the amount of trips requested.

\subsection{Statistical Analysis on Estimated Optimization}

In this section, average calculations on values that represent important aspects about public transport in Palmas will be discussed, based on data released by the service's own management company, news portals and the city's regulatory agency. All this, with the main objective of reaching the ideal amount of vehicles so that the profit with the service is not impaired or that for the value of the ticket is not at least increased.

According to the G1 Tocantins portal [14] a new ticket price may be charged and is being discussed as to its value, which may be R\$ 4,09 up to $\mathrm{R} \$ 4,26$, ranging from 0,26 up to 0,41 cents of increase. Considering the image 1 in the last 6 years, we have an average increase of 0,36 cents in passenger ticket per year, that is, it may cost in a mean $R \$ 4,21$ by 2021 , following the trend line of increase from the graph.

According to the report published in a article of a portal [7] and created by Agency of regulation of Palmas (ARP), the public transport system of the city serves about 1 million and 700 thousand passengers per month. So considering this sample of users and the price of the current ticket, the company (Seturb) collects about $\mathrm{R} \$$ $6,545,000$ per month and that with this average increase for next year, can reach $\mathrm{R} \$ 7,157,000$. Therefore, optimization should ideally be able to save the difference of about $\mathrm{R} \$ 600,000$ on the application of the selected problem.

The city's bus fleet travels around 1,041,390 kilometers per month [26]. As ARP reported that 190 buses are destined for public transport in the city, each bus runs approximately $5,481 \mathrm{~km} /$ month. According to a report created by the city hall of Cricima - SC [9] to identify the cost of the public transport system for the passenger, a heavy bus uses about 0.475 liters of fuel per kilometer, ie wheel on average $2.1 \mathrm{~km} / \mathrm{l}$, which is also used with the same model by Palmas (Tourino S Marcopolo chassis Volkswagen or Mercedes).

So, considering this data of fuel consumption per kilometer by the bus used in the public transport fleet, each vehicle in the fleet spends about 2,610 liters per month on diesel. The average price of fuel this month in Palmas according to the Foundation for Consumer Protection and Defense (Procon) [24] is about R $\$ 3.290$ per liter, so each bus spends on average per month on diesel, around $\mathrm{R} \$ 8,586.90$ and in total $\mathrm{R} \$ 1,631,511$ with the fleet.

As seen, the ideal is to save about R $\$ 600,000$ with the bus fleet. With the report cited earlier by the city hall of Cricima on its public transport system, these studies indicate that the fuel of the bus fleet represents about $20 \%$ of the final costs of the service, in which it is part of the variable costs that represent $32 \%$ of the total, against $63 \%$ of fixed costs and $5 \%$ of taxes.

So if consider R\$ 1631511 spent on fuel being equal to $20 \%$ of the final costs, the variable costs that represent all the expenses of maintenance and operation of the vehicles, which involves fuel, lubricants and auto parts, are equal to $\mathrm{R} \$ 2,610,418$, so finally, with the final value of the variable costs, each vehicle spent around $\mathrm{R} \$$ 13,739 per month to make public transport trips in the city. So, to save on average $R \$ 600,000$ applied in the optimization of the amount of buses used in public transport of Palmas, the expenses of variable costs can not exceed about $\mathrm{R} \$ 2,010,000$ and for this, the fleet of 190 buses should ideally reduce to 146 buses, that is, use only $76 \%$ of the fleet currently used, thus spending $\mathrm{R} \$ 2,005,894$ with variable costs.

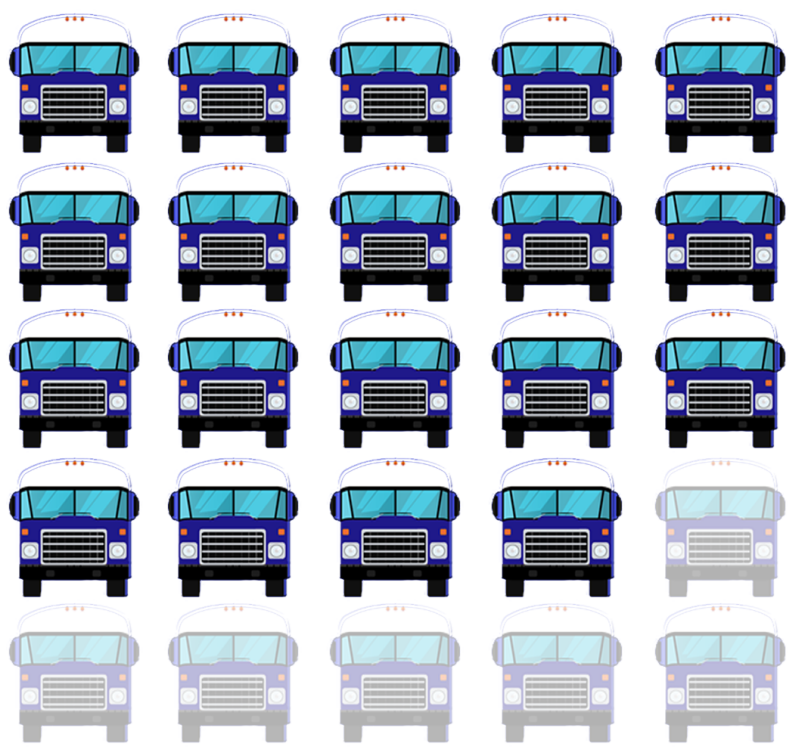

Fig. 2. Optimal bus use ratio. For every 25 vehicles used in the current proposal, the optimal optimization recommends using 19 buses. 


\section{CONCLUSIONS}

It was observed that the numerous works that used at least Iterated Local Search, but found several other metaheuristics also applied in similar scenarios. Therefore, our future work is the computational implementation of the mathematical formulation of the problem in the actual situations proposed, as well as the analysis of the results. As input of this algorithm, we will have the departure and arrival times of each trip to be made by the buses, being in total 10,419 trips made per week and 93 total lines operating, also observed in the image 3 with the daily information about the trips.

\section{Daily number of trips made by public transport from Palmas - TO}

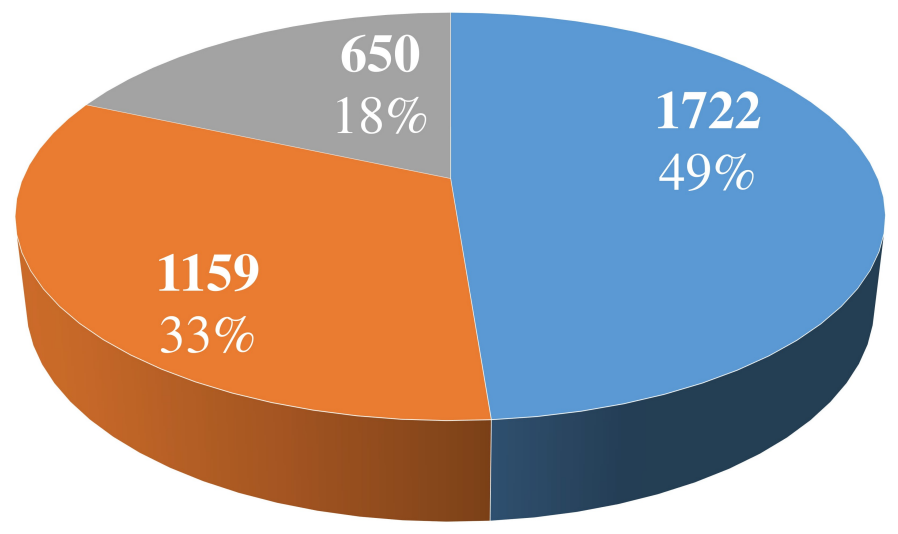

Workweek $\square$ Saturday $\square$ Sunday

Fig. 3. Representation of the percentage of urban public transport trips made daily, in which the referent vehicles that make the trips depart from 35 different points which are called garages.

In the statistical analysis of the estimated optimization it is observed that ideally about $76 \%$ of buses should remain in the daily urban public transport service of Palmas. So we have three ranges of results that we can expect from metaheuristics, as observed in the image 4 for processing and result more than 190, the problem was not optimized, because it uses a greater amount of buses than the existing, for results between 190 and more than 146 the problem was optimized, but not ideally, because it would show savings, however, not expected, and for result between 146 or less we have the ideal optimization, which proposes the desired economy.

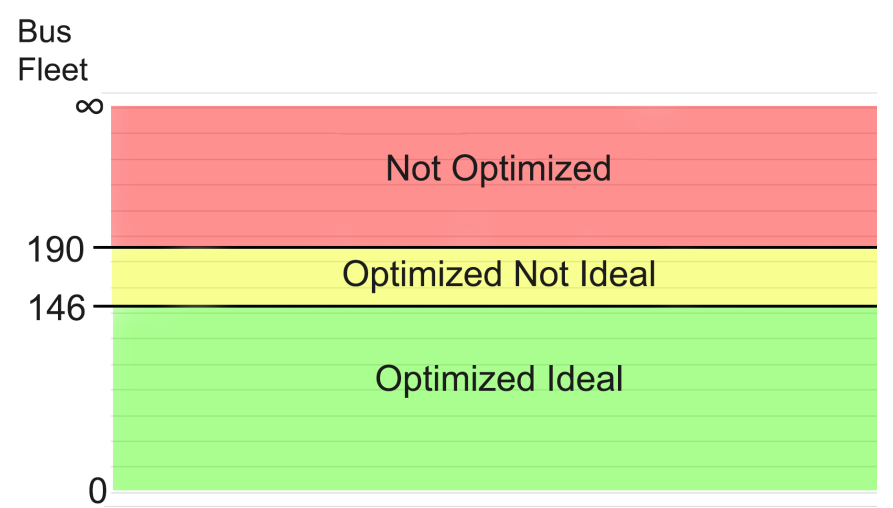

Fig. 4. Range of possible processing results estimated by the metaheuristic. Red - Not Optimized for results greater than 190; Yellow - Optimized Not Ideal for results under 190 and over 146; Green - Optimized Ideal for results under or equal to 146 .

\section{REFERENCES}

[1] Cssio Roberto Arajo, Elva Oliveira Couto, and Ricarlo Martins Reis. Problema de programao de veculos. 2002.

[2] E. Biondi and P.C. Palermo. A heuristic approach to combinatorial optimization problems. 1973.

[3] Lawrence Bodin and Bruce L. Golden. Classification in vehicle routing and scheduling. 1981.

[4] Bruno Andr Blume. Mobilidade urbana. https://www.politize.com.br/ mobilidade-urbana-transito-problemas/ 2016.

[5] G. Clarke and J. W. Wright. Scheduling of vehicles from a central depot to a number of delivery points. August 1962.

[6] Richard Congram, Chris Potts, and Steef Van De Velde. An iterated dynasearch algorithm for the single-machine total weighted tardiness scheduling problem. INFORMS Journal on Computing, 14:52-67, 022002.

[7] ct. Por alta de insumos, reajuste de funcionrios e novos nibus, seturb pediu $\mathrm{r} \$ 4,2019$.

[8] G. B. Dantzig and J. H. Ramser. The truck dispatching problem. pages 80-91, October 1959.

[9] Prefeitura de Cricima. Estudo dos custos do sistema de transporte pblico de passageiros de cricima, 2020.

[10] Deniz Tursel Eliiyi, Arslan Ornek, and Sadk Serhat Karakutu $\mathrm{k}$ b. A vehicle scheduling problem with fixed trips and time limitations. pages 150-161, 2008.

[11] Bogdan Filipic and Darko Zupanic. An Evolutionary Algorithm for a Non-standard Scheduling Problem. Artificial Neural Nets and Genetic Algorithms, 1998.

[12] B. A. FOSTER and D. M. RYAN. An integer programming approach to the vehicle scheduling problem. 1976.

[13] G1. A cada 1 hora, 5 pessoas morrem em acidentes de trnsito no brasil, diz conselho federal de medicina, 2019.

[14] G1 Tocantins. Nova tarifa de nibus comea a ser discutida; propostas vo de r4,09ar 4,26. https://g1. globo.com/to/tocantins/noticia/2020/03/04/ nova-tarifa-de-onibus-comeca-a-ser-discutida-propostas \begin{tabular}{l|l} 
ghtml 2010. &.
\end{tabular} 
[15] Antnio Gaspar-Cunha, Ricardo Takahashi, and Carlos Henggeler Antunes. Manual de computao evolutiva $e$ metaheurstica. Universidade de Coimbra, first edition, 2012.

[16] IBGE - Instituto Brasileiro de Geografia e Estatstica. Palmas. https://cidades.ibge.gov.br/brasil/to/palmas/ historico 2014.

[17] IBGE - Instituto Brasileiro de Geografia e Estatstica. Frota de veculos. https://cidades.ibge.gov.br/brasil/to/ palmas/pesquisa/22/28120 2018.

[18] S. M. Johnson. Optimal two -and three-stage production schedules with setup time included. 1953.

[19] Helena Loureno, Olivier Martin, and Thomas Stützle. A beginner's introduction to iterated local search. pages 1-11, 06 2001.

[20] Helena Loureno and Michiel Zwijnenburg. Combining the Large-Step Optimization with Tabu-Search: Application to The Job-Shop Scheduling Problem, pages 219-236. 011996.

[21] Vincius Veloso de Melo. Tcnicas de aumento de eficitncia para metaheursticas aplicadas a otimizao global contnua e discreta. $\mathrm{PhD}$ thesis, Instituto de Ciłncias Matemticas e de Computao, Universidade de So Paulo, So Carlos, 122009.

[22] H. Muller-Merbach. Combination programming:methods and applications. pages 19-43, 1974.

[23] Ibrahim Osman and Gilbert Laporte. Metaheuristics: A bibliography. Annals of Operational Research, 63:513-628, 10 1996.

[24] Procon. Pesquisa preo combustvel - palmas, 2020.

[25] Melvin E. SALVESON. On a quantitative method in production planning and scheduling. 1952.

[26] Seturb. Quantos km rodamos por młs?, 2019.

[27] Bingqiang Situ and Wenzhou Jin. Study on the vehicle scheduling problem in transportation system. 2009.

[28] Gleidson Fonseca Soares, Gustavo Peixoto Silva, Euler Horta Marinho, Emiliana Lopes Simes, and Marcone Jamilson Freitas Souza. Otimizao no sistema de transporte pblico. 2006.

[29] Maria Teresinha Arns Steiner, Luzia Vidal S. Zamboni, Deise M. Bertholdi Costa, Celso Carnieri, and Arinei Lindbeck da Silva. O problema de roteamento no transporte escolar. 2000.

[30] Thomas Stützle. Local search algorithms for combinatorial problems - analysis, improvements, and new applications. In DISKI, 1999.

[31] TV Anhanguera. Palmas registra 30 mortes por acidentes de trnsito entre janeiro e agosto desse ano, 2019.

[32] Ya Yang, Stephan Kreipl, and Michael Pinedo. Heuristics for minimizing total weighted tardiness in flexible flow shops. Journal of Scheduling, 3(2):89-108, 2000. 